\title{
Covid 19 and Challenges in Higher Education: An Empirical Analysis
}

\author{
https://doi.org/10.3991/ijet.v16i15.23005 \\ Bibhu Prasad Sahoo, Ankita Gulati $\left.{ }^{\bowtie}\right)$, Irfan Ul Haq \\ University of Delhi, Delhi, India \\ aankita.gerediffmail.com
}

\begin{abstract}
Over the years the global economy, including India, has undergone a profound change and observed a pioneer role of innovation and technology in every sector. Rapid technological dissemination has seen human or physical touch points being replaced by digital interface. With digitization happening everywhere, it becomes all the more important for the education sector to adapt it in order to keep pace with the challenging world. With the onset of the global pandemic of Covid-19, the only option left with the education sector is to switch to online classes for its smooth and continuous working. This research aims to investigate the challenges that are faced by the students and their level of satisfaction from these classes. The study is based on primary data collected from 700 students of various colleges across Universities in India. The study employs regression models, crosstabs, and various other descriptive statistics for analysis of the data. The findings of the study suggest that the students face a lot of glitches while learning from the online mode of education and would need time to adjust. The research also provides an insight on the scope and the future of online education.
\end{abstract}

Keywords - Information and Communications Technology (ICT), digitization, machine learning, smart classes, online education, Covid-19

\section{Introduction}

The temporary closure of schools, colleges, and educational institutions over the last few months has impacted more than a billion children globally as an effort to contain the contagion of Covid-19. Fortunately, education did not move to cessation; instead, it has moved towards online mode. However, the problem is accentuated due to the existence of socio-economic variances globally in terms of availability of internet and the suitable technology.

To stop the spread of the COVID-19, numerous countries have employed deterring measures to lessen gathering and formations of crowds. As a result, the schools and colleges are not permitted to open. The impact is visible when, at the peak of the crisis, almost 1.6 billion children in 195 countries globally are not allowed to study in their classrooms. The problem is that the longer the closure of these institutions, the more is the potential loss of 
educational prospects. Also, it leads to a latent loss of human capital and enfeebled economic opportunities in the long run. Providentially, this crisis could not stop education, though it has brought many changes to it. The institutions have been looking for various unconventional ways to slacken the closure's impact and offer continuation of education. The use of technology, mainly the online classes and electronic textbooks, is currently considered as the best solution to continue with the working of this sector.

\subsection{Impact on education}

Over $60 \%$ of the student population got impacted by the total closure of schools and colleges. Millions of students are affected in those countries too which have implemented localized closure. So as to sustain education and learning process, the institutions have decided to set up the online classroom system. European Commission has started funding for the advancement of online learning at various levels of education in the country.

As per UNESCO [1] report on COVID-19, there is an enormous impact on education. UNESCO has monitored the policy responses that are positioned to contest COVID-19 and its influence, such as closure of schools. An interactive dashboard is created by them. The dashboard visualizes the impact since February 2020. It represents the number of learners who are affected studying in the pre-primary, primary, lower-secondary, and upper-secondary levels of education. As per the report around $68 \%$ of the total enrolled learners are affected globally.

The World Bank [2] has created a similar dashboard to visualize the impact of COVID-19 on education across the world. The dashboard represents the position of the schools and the number of students who are affected in the pre-school, primary, secondary level of education in every country. Around 1 billion students are affected due to full closure and around half-a-million affected due to partly closing the schools.

\subsection{Transition to digital education}

As per the survey steered by UNESCO, of the 61 countries questioned most of them have adopted the system of online education. The teaching activity is commenced and is going on digital platforms with the schools, teachers and learners using the e-learning resources. However, there are few exceptions; Sweden has not closed its primary school and; Belgium and Norway have opened its school facilities partly for parents who are working in essential service sectors. Furthermore, the governments globally are trying its level best to help institutions to provide basic infrastructure for offering basic learning opportunities for the students.

In 2015 the European Data Portal has used the data collected by the World Bank and piloted a survey with the help of the Organization for Economic Co-operation and Development (OECD) [3]. The survey results display the number of students affected due to the obstructive measures on schools \& colleges and the availability of internet 
facility \& technology in the European countries. As per the survey, the digitized infrastructure is not much developed in Europe. As per the estimates made globally, around 800 million students do not have computer in their household, 700 million lack internet accesses at home. There are around half-a-million who dearth mobile $3 \mathrm{G}$ or $4 \mathrm{G}$ network coverage. It is for sure that the families who do not have any internet experience are at a significant detriment during the crisis. This is often witnessed in already disadvantaged homes.

As per the estimates made by International Telecommunication Union (ITU), around $83 \%$ of African houses do not have internet access in their homes. During the previous health emergency of the Ebola epidemic, the influence on education is expected to be utmost disturbing in the countries where the dropout rates were high having low learning outcomes.

Apart from having internet accessibility, one also requires a quiet place to study and a separate device for the same. It becomes more difficult for families with many children, who are taking online classes, as they might not have a dedicated device per child. The reason is that a large difference between socio-economic statuses of people exists within and across nations. Hence, it becomes difficult to follow a standardized way of teaching.

The equation's counterpart has also been affected. The question arises as to how well the academic institutions are fortified for online classes and how sound teachers are primed for and engaged in online teaching. Teachers are required to make quick amendments in their teaching-learning methods so as to live up to the expectations. They need to look for the best approach to finish the curriculum's full syllabus via completely new and different way of teaching. Hence, it becomes important to understand the inculcation and adoption of this new and advanced method of learning from the point of view of the students as well as the teachers.

\section{Review of Literature}

For a long time now, various researchers have tried to study the inclusion of Information and communications technology techniques in education in different developed and developing nations. With a force of pandemic situation, such methods have to be adopted globally in the perspective of the available resources. Thus, this has become an area of interest for research. Few of the research papers have been mentioned, and their work has been admired.

As cited in [4], the UNESCO international community's views about the common problems faced in education due to indulgence in information and technology. ICT in education offers quick transfer of information leading to growth in personality and learning the skills. This helps the learners in understanding \& appreciating each other and working towards the betterment of the society at large. In the paper [5] it is cited that the developing nations do not have full access to the technology. Besides, it also faces the structural and behavioral hindrances.

As stated in [6] support the usage of information, communication, and technology in education as it improves and provides better learning opportunities to students. The 
paper also emphasized that the teachers should be given the knowledge of technology as a basic skill to teach. According to [7] there is enough evidence that information and technology brings in better learning outcome. This is possible if active and collaborative practices are being followed. As per Ref. [8] the ICT techniques in education act as an obstacle for professionally developing teachers and teacher training programs should be arranged for the same.

As per Ref. [9] by using information and communications technology in schools, the students get motivated to study leading to improved learning outcomes. As per the research, technology benefits students to remain updated and help them adapt to changes. It is emphasized in Ref. [10] that universities worldwide should rethink and upgrade their mission and strategy to adapt to the technological changes. A lot of effort will be required to bridge this gap, i.e., the gap between the traditional and the modern working methods. Ref. [11] mentions that the nations using the information and technology in education hold an advantage against those who do not use it. As stated in [12], it is revealed that students enjoy and look for a rich technical environment. According to the survey, the high school students were infuriated by the inadequate access to computers and other resources, as oppose to science students who were offered these resources.

As per Ref. [13, 14], in their research, concludes that organizational change and transformation in leadership happens with the introduction of digitalization in the concerned sector. Ref. [15] researched to understand the application of technical and professional studies in the Indian education sector. As per the research Indian youths are now getting dependent on internet, video lectures and online books to study. Also, the author has discussed the usage of smartphones in education technology.

The research [16] has concluded that the data analysis results ease the recruitment process during placements using the student's grade and other socio-demographic variables like age, class grade, gender, extra co-curricular activities, etc. in the Ref. [17] the study is done on the prediction and performance analysis on educational data mining. It is elucidated that machine learning methods helps in finding solutions to the problems in a more informative and enlightening way. In the study conducted in [18] information was gathered on the influence of digitization in education from various educational institutions' teachers at the primary and secondary levels. The results show that most of the teachers favor the digitization of education as it helps the students gather more knowledge and increases their learning of technology. As stated in [19] it was revealed that education's speed and quality improves with technologybased learning and educational activities. It describes that the virtual tutorial programs helps to accelerate the process of information propagation, making it more structured and flexible and offers a metacognitive understanding to the students.

As per [20] work is done on the Application of Machine Learning algorithms to improve the education system and introduced a machine learning approach to predict students' performances using different machine learning algorithms. As per in [21] there is a presence of huge gap in the assimilation of digital technologies and resources in the education system in Europe. As stated in [22] the governments should collaborate with various stakeholders, businesses, and individuals who believe in 
inculcation of technology in several sectors including education so that everyone should reap the benefits from it.

The Ref. [23] mentioned that the two terms, digitalization and digitization have different interpretations. Digitization is the process used for the analogical approach of information. However, digitalization refers to the changes allied with the solicitation of digital technology. In the research article [24], it is mentioned the impact of digitization on the education sector. The research follows a descriptive study approach based on the secondary data. As per the article, the inculcation of digitization in India's education sector will make it at par with the global institutions. Also, with the manifestation of e-resources and e-libraries, the hurdles in research will be erased. With more and more progress in the technical education system, one can easily connect with the system's counterparts without being physically present in the classrooms using webinar method. Technology also helps provide access to education even in the country's remotest part with easy solutions to distance learning. Also, the technology helps in reducing the cost of learning and increases the accuracy in the field of education setting.

As stated in [25] it is emphasized that educational institutions should work fast to adapt to the changes required specifically in the current situation of Covid-19, bearing in mind the maintenance of quality of education. Any hesitance to the change will impact the entire generation and will not be prolific to academic institutions. As per the survey study [26], there is a difference in the availability and accessibility of the e-learning resources among males and females in Malaysian Universities acting as a deterrent to learning through digital platforms. Based on the responses of students of various universities in West Bengal [27] mentioned that many students are facing depression and anxiety due to an indecorous study environment and lack of access to resources in the times of the pandemic. The paper [28] stressed that there is a need to reduce mental strain and pressure and bring innovation to the teaching-learning process. As stated in [29] it was revealed that students with hearing disabilities have their own glitches while learning through online mode. In the paper [30, 31] voiced their fear that students at large are already facing distress due to the pandemic.

It is very well observed that the presence of information, communication and technology has always pushed up the effectiveness in learning. Also, the instructional design based on these technologies brings in feasibility and flexibility promoting an enriched environment of learning [32, 33, 34].

With the view of research done in the past, it becomes essential to discover how this pandemic has forced upon us the concept of online education and finding out what are the related problems. Also, the research will help us to decide on whether this arrangement should be continued in the future or not.

\section{Objectives and Hypotheses}

The research aims to find out the students' challenges while studying from home, to identify the gaps in the system and then take appropriate measures to improve it. For this purpose, data has been collected from more than 700 students who are 
currently taking online classes. The data is being studied at the aggregated level to derive insights and draw actionable strategies for the near future and its impact, if any, on the online education system.

Besides the aforesaid general-purpose, the specific objectives of the study are: to understand if the students are satisfied with this new method of learning and online assessment. The study further examines the impact on health due to following this online mode; to find out whether all the students have easy access to technology and the importance of communication and personal touch in the process of learning and education. In order to study the objectives mentioned above, the following hypothesis is established.

H1: There is a significant relation between satisfaction among students from online classes and factors like importance of personal touch and communication in learning, difficulty in understanding in classes, impact on health, assessment of the modes used, accessibility and understanding of technology.

\section{$4 \quad$ Limitations of the Research}

The present study is based on the responses of the students only. Hence, the study highlights the viewpoint of the students and does not take into account the teachers' point of view towards this system of learning. The research also suffers the limitation of few respondents and that too from specific region. The spectrum of the respondents taken was well equipped with the latest technology and appliances. The research also suffers the basic shortcomings of survey research such as biased answers, lack of personalization, misinterpretation of questions, etc.

\section{$5 \quad$ Methods and Materials}

The research methodology used in the study is quantitative. In order to examine relationships and understand the cause and effect interactions among variables, a systematic study is followed. The information is collected by questionnaires which were self-administered and distributed to students belonging to different universities through various online mediums. The selected technique is descriptive surveys because it provides accurate characteristics of the variables, say the opinions, behavior, and beliefs of the respondents. The study was steered online \&around 700 student's data was collected. The data analysis of this research will be presented quantitatively. Data will be analyzed using regression models, crosstabs, and various other descriptive statistics. The use of excel spreadsheets and R as the software is done to analyze the data. The rationale for choosing such a research methodology is to find out that the acceptance of this new method among students and its continuation in the future.

Since the preference is a binary classifier (yes or no), a logistic model is used. The regression equation for the model is:

$$
p=\frac{1}{1+e^{-Z}}=\frac{1}{1+e^{-\left(X_{0}+\beta_{1} X_{1}+\beta_{2} X_{2}+\cdots \cdots \cdots \cdots+\beta_{n} X_{n}\right)}}
$$


where,

$\mathrm{p}=$ probability that dependent $=1$, dependent variable is future preference for online classes

$\mathrm{X}_{1}, \mathrm{X}_{2}, \mathrm{X}_{3}, \ldots \ldots \ldots \ldots, \mathrm{X}_{\mathrm{n}}$ are the independent variables or responses on survey questions

Entire data analysis is performed in open source R software. The study is based on application of advanced machine learning algorithms to derive meaningful insights and statistical significance of the important drivers impacting the studies in higher education.

The survey questionnaire is designed on 18 questions in which future scenario preference for taking or not preferring online classes was kept the dependent variable while the rest 17 parameters were kept as independent features. The first step is to rank each of the independent covariates in decreasing order of their importance or relevance to define the dependent variable, in order to keep only top 10 most essential drivers for further analysis. For this purpose random forest algorithm is used. It is one of the widely applied machine learning techniques in binary classification. It is based on the concept of decision trees where a large number of decision model trees are present, which are relatively uncorrelated, that are coming together to form a singular model. The model will outperform any individual constituent model because each model cancels out the bias and error of the other model as they are independent. Then the mean decrease in the accuracy parameter, which calculates the decrease in prediction power of the variable when it is randomly permuted in the model against its original ordering with the dependent variable, is checked. The variables with higher values become more critical.

Since the response variable is a binary outcome of whether online classes will be preferred in the future or not, for this logistic regression is used to predict the outcome depending upon various demographic, attitudinal, preference, and other impact variables. Given that a model may be biased with high variance, so in order to enhance the logistic regression model bootstrap aggregation or bagging is used. It is a type of ensemble model, a category of advanced machine learning algorithms which is made of - bootstrap. It means approximating a quantity from a sample of data with or without replacement $\&$ aggregation, which essentially repeats the process multiple times and individual model predictions are aggregated to make a final accurate prediction. Bootstrap aggregation combines various ensemble models via mean or mode, depending on the problem. In this case, an average of predictions across each model is taken. The method helps in reducing the variance in the model's forecast from the small sample. It mitigates the issue of small sample size by repeating the draw of sample $n$ number of times from a given population so that over time the average replicates the actual population. Bagging can be done in two ways. Firstly, subsampling in the number of observations and secondly in terms of covariates which are the independent variables. 


\section{$6 \quad$ Analysis and Interpretation}

The survey conducted tries to assess various factors impacting studies in higher education and seeks to decipher various challenges faced by the students and what they would like to see as an improvement in the online education system.

More than 700 respondents took part in the digital format survey which was distributed through online digital mediums like email and social networking sites and college classrooms portals. The survey data was kept completely anonymous with no personal data being captured from the individual participants. A total of 18 questions were asked which included information like technology, cost factors, understanding aspect and impacts of doing study from home.

Figure 1 presents some high level survey exploratory data analysis which reveals the responses and preferences. As can it be comprehended from the data, $56 \%$ of the students said that they are not completely satisfied with the online system. Thus the paper endeavors to enlist the reasons for the same and offer insights for better future management and the problem areas to target. Given the data revolution and tech savvy generation today, more than three-fourth of the respondents had access to the requisite technology and almost similar number (71\%) had no difficulty in understanding the same. While the students were divided on whether they were saving on costs but they had clearly pointed out in $51 \%$ majority that their health was impacted in a negative manner due to studying from home and less travel.

Almost in a unanimous decision, $85 \%$ and $93 \%$ students mentioned that personal touch and peer communication is very important for a holistic development respectively. Further deep diving on the issues $71 \%$ felt a communication gap with the teachers due to absence of one to one or personal touch while $61 \%$ felt that their personality growth was impacted. Approximately $80 \%$ of the students were having difficulties in concentrating during the classes which could be either because of the lack of study atmosphere in home or because similar proportion of students also mentioned difficulty in understanding the concepts online which was much better in a physical classroom environment. The credit should definitely go to everyone including the teachers, administration and the students as more than $90 \%$ of the students have highlighted that regular classes are being held and a big subset of about $78 \%$ students have mentioned that their attendance has improved may be because they do not have to travel daily and are taking classes conveniently from home.

The results from the survey are depicted in the following charts: 
Paper-Covid 19 and Challenges in Higher Education: An Empirical Analysis
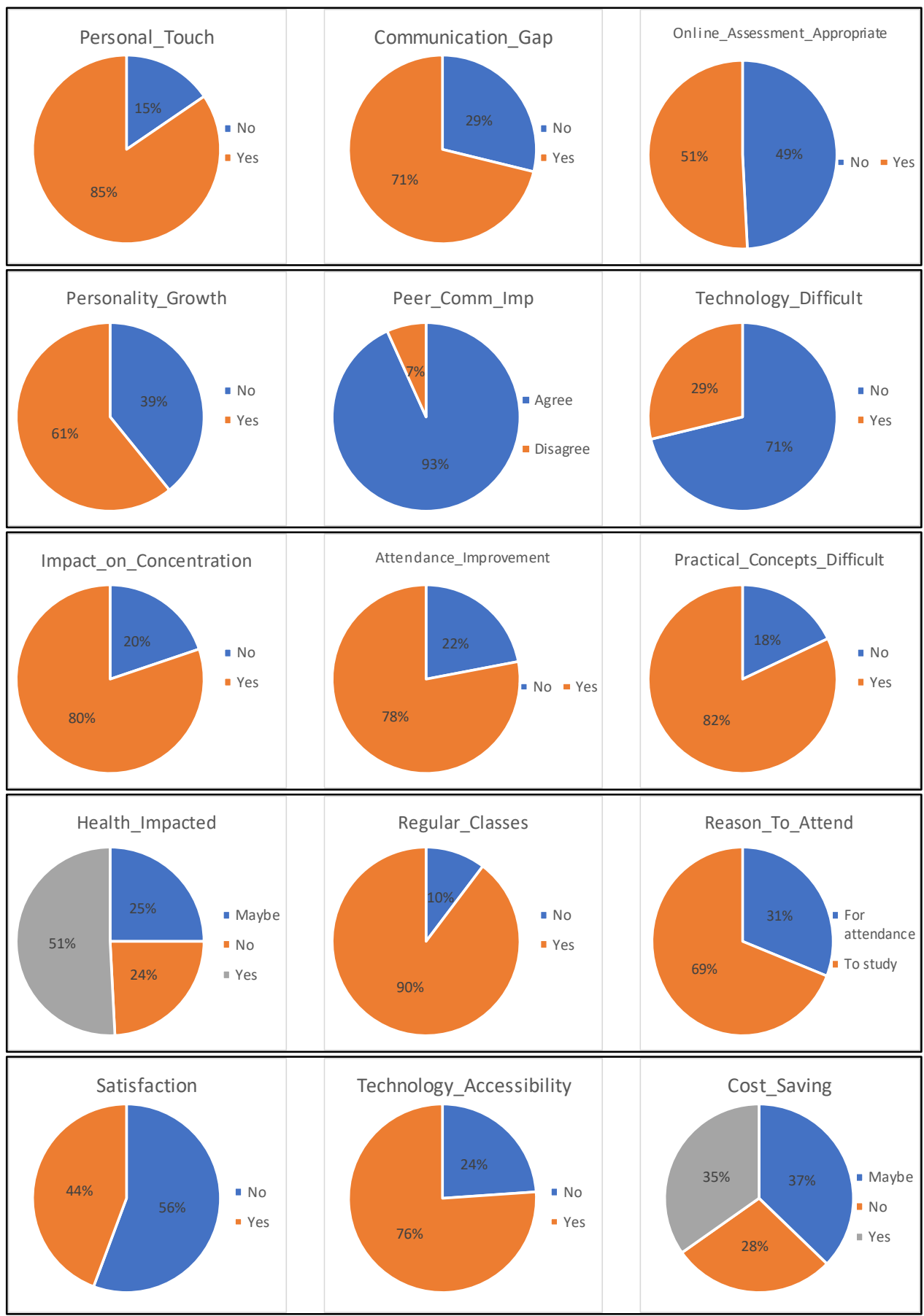

Fig. 1. Graphs representing exploratory data analysis from the survey data of $\sim 700$ students 
In order to rank each of the independent covariates in decreasing order of their importance or relevance to define the dependent variable, random forest algorithm is used. This helps in obtaining top 10 most essential drivers for further analysis. Random forest test ran in $\mathrm{R}$ on all 17 variables together; to build 100 trees each taking a sample of $70 \%$ random values from the pool of 700 observations. Then the mean decrease in accuracy parameter is checked. Higher the value, the more important the variable is. The table 1 depicts the output from the random forest variable importance function, where highlighted in bold are the top 10 drivers that is finally selected for the model.

Table 1. Top drivers of the model selected

\begin{tabular}{|c|c|c|}
\hline S.NO & VARIABLE & IMPORTANCE \\
\hline 1 & Benefit/Loss_of_System & 50.60 \\
\hline 2 & Cost_Saving & 43.66 \\
\hline 3 & Communication_Gap & 43.31 \\
\hline 4 & Online_Assessment_Appropriate & 43.04 \\
\hline 5 & Understanding_Difficulty & 41.04 \\
\hline 6 & Practical_Concepts_Difficult & 38.50 \\
\hline 7 & Reason_To_Attend & 33.64 \\
\hline 8 & Impact_on_Concentration & 31.57 \\
\hline 9 & Personal_Touch & 30.54 \\
\hline 10 & Health_Impacted & 25.21 \\
\hline 11 & Technology_Difficult & 19.43 \\
\hline 12 & Technology_Accessibility & 15.69 \\
\hline 13 & Attendance_Improvement & 12.38 \\
\hline 14 & Regular_Classes_Held & 10.93 \\
\hline 15 & Peer_Communication_Importance & 8.84 \\
\hline 16 & Online_Classes_Attending & 4.76 \\
\hline 17 & Impact_on_Personality_Growth & 4.73 \\
\hline
\end{tabular}

From the table 1 it can be seen that the most important driver for satisfaction index is how the student feels he is impacted from the online education system. Cost savings, communication gap, and personal touch while studying are few more important buckets to be kept in mind while delivering education or classes through online mode. Other aspects to be kept in mind are the drivers motivating the students to attend classes - whether it is to study and improve knowledge or just for attendance. Students also seem to be thoughtful about the online assessment method as that impacts their final evaluation and marks. Difficulty in understanding seems to be the driving force behind the decision and satisfaction index.

Given that all or most students had access to the requisite technology for online classes and they all are well versed with; it doesn't seem to be an important factor in determining the students' preference. Although, the results would have been different if the chosen population does not have an easy access to technology. Attendance also seems to be a not so important factor in determining the satisfaction as most students 
were taking classes for understanding and knowledge building. Peer communication and impact on personality growth also seem to be an important variable but the machine learning algorithm tells that they seem to be covered for by personal touch and would only lead to an increased covariance between the independent variables or what is called as VIF amongst the covariates.

In the approach, while building the bagged logistic regression, for each iteration of the model a random sample of about $70 \%$ observations is taken to ensure equal weights to each observation. This process was repeated 100 times which means $\sim 500$ observations were picked out of 700 observations randomly and then repeated 100 times. This gave 100 different datasets of 500 observations each with a given set of dependent and independent variables. Then secondly, in terms of the covariates, since the model is a classification model, benchmark number of predictors ( $p$ ) to be used is about square root of total number of variables $(\mathrm{n})$, which is:

$\mathrm{p}=(\mathrm{n})^{\wedge(1 / 2)}$

which corresponds to $(10)^{\wedge(1 / 2)=3.16}$, round off to 3 .

Now post dimension reduction through random forest, the database is left with top 10 predictors, so a sample of 3 random variables at a time is taken. This meant that 120 pairs of combinations of features are generated, that is used to build the model which is ${ }_{10} \mathrm{C}_{3}$.

Combining the steps one and two from the above approach, it meant building $120 *$ $100=12,000$ models of logistic regression on random samples of survey data collected from 700 respondents. Building thousands of models requires a lot of run time and computing power, hence a concept of parallelization in $\mathrm{R}$ is used, which is exactly used for the purpose of automating, fastening and doing parallel processing. It involves distributing the tasks separately to the cores on the computer machine to work parallelly. In this case one pair of combination for which 100 iterations would be run is a task and the laptop used had 8 cores which meant that at a single time 8 models could be built. R uses the library "doParallel" to run this using lapply function supplemented with parallel cluster cores.

The results are shown in table 2 .

The table 2 has three columns - 1) VARIABLE, which is the independent driver with the coefficient for each possible class of value, 2) ODDS, which represent the \% change in odds of the dependent variable for 1 unit increase in independent or change in class from the base position, 3) LOG_ODDS, which is the direct coefficient from the log model and gives the change in log odds.

It can be seen that if the students believe that there is a communication gap between them and teachers or the system and they feel disconnected then the odds (probability of success by failure) decreases by $79 \%$ versus if they are not facing any communication gap. This basically implies that the odds of being satisfied with online education system decreases by $79 \%$ if students feel a communication gap. If students are saving costs due to less travelling then odds of being satisfied increases by 3 times whereas if they don't feel any cost incentives, then odds decrease by $33 \%$. Due to being online constantly and sitting on laptop there is a health discomfort and strain on eyes, which leads to a reduction of $36 \%$ in odds of being satisfied whereas students are fine health wise, then it can surge the chances by $88 \%$. The biggest incentives for 
the students to come online is the reason, if it is studies then odds jump by almost 4 times versus when the reason to come online is purely for attendance. Also, if the students are satisfied with the online evaluation criteria and methods, then it leads to satisfaction and jump in odds by $397 \%$ or roughly four times. Personal touch, understanding of the concepts and concentration are some of the other factors that determine the success of online education system.

Table 2. Results of the Logistic model

\begin{tabular}{|l|c|c|}
\hline \multicolumn{1}{|c|}{ VARIABLE } & ODDS & LOG_ODDS \\
\hline Communication_Gap_Yes & $-79 \%$ & -1.584 \\
\hline Cost_Saving_No & $-33 \%$ & -0.419 \\
\hline Cost_Saving_Yes & $291 \%$ & 1.342 \\
\hline Health_Impacted_No & $88 \%$ & 0.609 \\
\hline Health_Impacted_Yes & $-36 \%$ & -0.456 \\
\hline Impact_of_Online_System_Can't say & $-85 \%$ & -1.933 \\
\hline Impact_of_Online_System_Loss & $-94 \%$ & -2.788 \\
\hline Impact_on_Concentration_Yes & $-73 \%$ & -1.331 \\
\hline Online_Assessment_Appropriate_Yes & $397 \%$ & 1.589 \\
\hline Personal_Touch_Yes & $-82 \%$ & -1.721 \\
\hline Practical_Concepts_Difficult_Yes & $-81 \%$ & -1.675 \\
\hline Reason_To_Attend_To study & $394 \%$ & 1.578 \\
\hline Understanding_Difficulty_Yes & $-75 \%$ & -1.395 \\
\hline
\end{tabular}

Finally, the accuracy of the models built is also checked and an average of all the 12,000 models is taken. This helps to get accuracy figure and the confusion matrix.

Table 3. Confusion Matrix

\begin{tabular}{|l|c|c|c|}
\hline \multicolumn{2}{|c|}{ CONFUSION MATRIX } & \multicolumn{2}{|c|}{ PREDICTED } \\
\cline { 3 - 4 } & & $\boldsymbol{Y E S}$ & $\boldsymbol{N} \boldsymbol{O}$ \\
\hline \multirow{2}{*}{ ACTUAL } & YES & 148 & 80 \\
\cline { 2 - 4 } & NO & 47 & 240 \\
\hline
\end{tabular}

The model gives an accuracy of $75.26 \%$. As can be seen in table 3 the confusion matrix is built of four components:

TP (True positive,148) - both actual and predicted are true

TN (True Negative, 240) - both actual and predicted are negative

FP (False Positive, 47) - predicted is positive, but actual is negative

FN (False Negative, 80) - Predicted is negative, but actual is positive

Out of bag accuracy of $75 \%$ for a model is pretty good and shows that the model does a pretty good job in predicting the response of the attributes outside the actual data points and works well on the predicted dataset. 


\section{$7 \quad$ Discussions and Conclusion}

The concept of education from distance using an online mode 'the new normal' is adapted by the parents, students and teachers across the world in this pandemic. As the educational institutions will be resurrecting soon, there could be two time lines against which modifications can be perceived. In the short-term, the educational institutions are required to ensure that adequate hygiene and measures for social distancing are followed and also have to ensure an environment of faith among parents to let their children back. Also, they are supposed to take into considerations the possible learning losses that might have occurred and how to compensate for the same. In the long-term, however permanent deviations could be seen in the educational systems. Adoption of technology in the system will be the first and foremost change that will happen. Also, with the technical inducement in the system, the educational institutions have to consider the privacy and protection of the children's personal data.

Even though the closure of schools has created disruption initially but over a course of time it has encouraged innovation in educational system and working. It is assumed that this crisis will have an enduring effect on the course of learning, innovation and digitization. The World Economic Forum has given three aspects in which these possible changes can be seen:

The crisis will hasten innovation in education. Those who are using the method of online learning and having access to internet and necessary technology already prefer this mode. With the availability of this insight, the educational institutions will try their level best to mend the productivity of the lessons by implementing new digital learning possibilities. These potential innovations will include increase in the platforms and resources for online learning. This will all happen in order to help students, parents, staff, school and its administration.

The crisis will foster partnerships. Over the past few years it has been seen that even private companies have interest in investing money in the educational sector. With the digitization of education public-private partnership can grow in importance. Also, this could create a path for large scale and cross industry cooperation for the improvement in this sector.

The crisis will create a digital divide. With digitization of education the quality of learning and education will depend on the internet accessibility and the required abilities to use it. The availability of necessary technology and platforms differ heavily per country. This inequality will lead to digital divide which could widen the gap of effectiveness of education across the globe and hence is not good for the world to grow together.

As per the research, currently most of the students are not much satisfied with the online learning method. They feel disconnected and also feel that there exists communication gap between them and teachers. They are also not content with the evaluation method used by the institutions. Also, the students are facing health troubles by attending continuous classes for long hours without breaks. The students have given significance to factors like personal touch, lack of understanding the 
concepts and poor concentration while attending classes. It is of high importance for students to learn from their peer which is again lost due to this arrangement.

Hence, on the basis of the research it is can be said this arrangement is not accepted whole heartedly by the students. However, a new hybrid educational system may transpire with both online as well as face-to-face classes happening together. Or there is another possibility that in the short-term online mode will be used and things will go back to its traditional way later. With the passage of time and more research in this field the larger-scale impact of this pandemic on education and its future can be understood.

\section{$8 \quad$ References}

[1] https://en.unesco.org/sites/default/files/unesco-covid-19-response-toolkit-remote-learningstrategy.pdf-

[2] https://www.worldbank.org/en/data/interactive/2020/03/24/world-bank-education-andcovid-19

[3] https://data.oecd.org/

[4] Stover, W.S. (1984). Information Technology in the Third World, Boulder, colo. Westview press. 1984

[5] Hanson. J, Narula, U. (1990), The new communication technology in developing countries. Published June 1, 2016 by Routledge. ISBN 9781138977020.

[6] Kelly, M.G. (Peggy), \& McAnear, A. (2002). National educational technology standards for teachers, preparing teachers to use technology. Eugene, OR: International Society for Technology in Education (ISTE) from https://www.scirp.org/\%28S\% 28351 jmbntvnsjt 1 aadkposzje $\% 29 \% 29 /$ reference/referencespapers.aspx $?$ referenceid $=24760$ 72

[7] Nelson, T. and Kuh, G (2004) Student Experiences with the information technology and their relationship to other aspects of student engagement, Paper presented at the Annual Meeting of the Association for Institutional Research, May 30 - June 3, 2004

[8] Jung, I. (2005). ICT-Pedagogy Integration in Teacher Training: Application Cases Worldwide. Educational Technology \& Society, 8 (2), 94-101.

[9] Mishra, R.C. (2005). Management of educational research, India: Published by APH Publishing Corporation, 2008 ISBN 10: 8176488542 / ISBN 13: 9788176488549

[10] Bratianu, C., Vasilache, S., \& Jianu, I. (2006). In search of intelligent organizations. Management \& Marketing, 1(4), 71-82.

[11] Stensaker, B., Maassen, P., Borgan, M., Oftebro, M. \& Karseth, B. (2007). Use, Updating and Integration of ICT in Higher Education: Linking Purpose, People and Pedagogy. Higher Education: The International Journal of Higher Education and Educational Planning, 54(3), 417-433. https://doi.org/10.1007/s10734-006-9004-x

[12] Beauchamp, G. and Parkinson, J. (2008). Pupils' attitudes towards school science as they transfer from an ICT-rich primary school to a secondary school with fewer ICT resources: Does ICT matter? Education and Information Technologies 13, 2 (June 2008), 103-118. https://doi.org/10.1007/s10639-007-9053-5

[13] Bratianu, C. (2010). A New Perspective of the Intellectual Capital Dynamics in Organizations. 1-21. 10.4018/978-1-60960-054-9.ch001.

[14] Bratianu, C., \& Anagnoste, S. (2011). The role of transformational leadership in mergers and acquisitions in emergent economies. Management \& Marketing, 6(2), 319-326. 
[15] Kumar, M. (2011). Impact of the Evolution of Smart Phones in Education Technology and its Application in Technical and Professional Studies: Indian Perspective. International Journal of Managing Information Technology, 3(3). https://doi.org/10.5121/ijmit.2011. $\underline{3304}$

[16] Umamaheswari. K., and S. Niraimathi (2013), "A Study on Student Data Analysis Using Data Mining Techniques". International Journal of Advanced Research in Computer Science and Software Engineering, Volume 3, Issue 8, August 2013.

[17] Thakar, P, Mehta. A, and Manisha (2015), "Performance Analysis and Prediction in Educational Data Mining: A Research Travelogue". International Journal of Computer Applications (0975 - 8887) Volume 110 - No. 15, January 2015.

[18] Tunmibi, S., Aregbesola, A., Adejobi, P. and Ibrahim, O. (2015), "Impact E-Learning and Digitalization in Primary and Secondary Schools". Journal of Education and Practice, Vol.6, No.17.

[19] Jaleel, S., Premachandran. P, A Study on the Metacognitive Awareness of Secondary School Students. Universal Journal of Educational Research 4(1): 165-172, 2016.

[20] Jaleel,S. and Premachandran. P (2016). A Study on the Metacognitive Awareness of Secondary School Students. Universal Journal of Educational Research, 4(1), 165 - 172. https://doi.org/10.13189/ujer.2016.040121

[21] Halde, R. R. (2016). "Application of Machine Learning algorithms for betterment in education system," 2016 International Conference on Automatic Control and Dynamic Optimization Techniques (ICACDOT), Pune, pp. 1110-1114 .https://doi.org/10.1109/ica cdot.2016.7877759

[22] Bejinaru, R. (2018). Assessing students' entrepreneurial skills needed in the knowledge economy. Management \& Marketing. Challenges for the Knowledge Society, 13(3), 11191132. https://doi.org/10.2478/mmcks-2018-0027

[23] Novak, J., Purta, M., Marciniak, T., Ignatowicz, K., Rozenbaum, K., \& Yearwood, K. (2018). The rise of digital challengers how digitization can become the next growth engine for central and Eastern Europe. Retrieved on July 30, 2019 from https://www.mckinsey.com/ /media/McKinsey/Featured\%20Insights/Europe/Central\%20a nd\%20Eastern\%20Europe\%20needs\%20a\%20new\%20engine\%20for\%20growth/Therise-of-Digital-Challengers.ashx

[24] Bloomberg, J. (2018). Digitization, digitalization, and digital transformation: confuse them at your peril. Forbes. Retrieved on August 28, 2019 from https://www.forbes.com/sites/jasonbloomberg/2018/04/29/digitization-digitalization-anddigital-transformation-confuse-them-at-your-peril/\#78e677fd2f2c.

[25] Jadhav. S.J | Mr. Shyamsingh V. Raghuwanshi (2018). A Study on Digitalization in Education Sector" Published in International Journal of Trend in Scientific Research and Development (ijtsrd), ISSN: 2456-6470, Special Issue | International Conference on Digital Economy and its Impact on Business and Industry, October 2018, pp.43-44. https://doi.org /10.31142/ijtsrd 18667

[26] Carey K (2020). Everybody Ready for the Big Migration to Online College? Actually, No. The New York Times. From (Retrieved on 24 July 2020).

[27] Shahzad, A., Hassan, R., Aremu, A. Y., Hussain, A., \& Lodhi, R. N. (2021). Effects of COVID-19 in E-learning on higher education institution students: the group comparison between male and female. Quality \& quantity, 55(3), 805-826. https://doi.org/10.1007 /s11135-020-01028-Z

[28] Kapasia, N., Paul, P., Roy, A., Saha, J., Zaveri, A., Mallick, R., Barman, B., Das, P., \& Chouhan, P. (2020). Impact of lockdown on learning status of undergraduate and 
postgraduate students during COVID-19 pandemic in West Bengal, India. Children and youth services review, 116, 105194. https://doi.org/10.1016/i.childyouth.2020.105194

[29] Harsha, $\mathrm{R}$ (2020). Covid -19 Lockdown-Challenges to Higher Education. 10.13140/RG.2.2.16290.25281.

[30] Manzoor, A. \& Ramzan, Q. (2020). Online Teaching and Challenges of COVID-19 For Inclusion of Persons with Disabilities in Higher Education.

[31] Gao J, Zheng P, Jia Y, Chen H, Mao Y, Chen S, Wang Y, Fu H, Dai J. Mental health problems and social media exposure during COVID-19 outbreak. PLoS One. 2020 Apr 16;15(4): e0231924. PMID: 32298385; PMCID: PMC7162477. https://doi.org/10.1371/ journal.pone.0231924

[32] Duan L, Shao X, Wang Y, Huang Y, Miao J, Yang X, Zhu G (2020). An investigation of mental health status of children and adolescents in china during the outbreak of COVID19. Journal of Affective Disorders, 275:112-118. https://doi.org/10.1016/j.jad.2020.06.029

[33] Suartama, I K., Setyosari, P, Sulthoni, S. \& Ulfa, S. (2019). Development of an Instructional Design Model for Mobile Blended Learning in Higher Education. In: International Journal of Emerging Technologies in Education, 14, 16, pp. 4-22. https://doi. org/10.3991/ijet.v14i16.10633

[34] Marrhich, A., Lafram, I,; Berbiche, N. \& El Alami, J. (2020). A Khan Framework-Based Approach to Successful MOOCs Integration in the Academic Context. In: International Journal of Emerging Technologies in Education, 15, 12, pp. 4-19. https://doi.org/10.3 991/ijet.v15i12.12929

[35] Zhang, Y., Chen, J., Miao, D. \& Zhang, C. (2018). In: International Journal of Emerging Technologies in Education, 13,07, pp. 111-123.

\section{Authors}

Dr. Bibhu Prasad Sahoo is an eminent professor in the University of Delhi. He is the head of the Department of Business Economics, SGTB Khalsa College. He has acted as a guide to numerous M.Phil and Ph.D students. He has made a vital contribution in the academic research in the field of commerce and management.

Ankita Gulati is a research scholar pursuing $\mathrm{PhD}$. and teaching as an assistant professor in the Department of Business Economics, University of Delhi. Her area of research interest lies in understanding the intersections between technologies and institutional/ public policy, with specific emphasis on the interrelationships between education, invention and innovation.

Irfan Ul Haq is a research scholar pursuing $\mathrm{PhD}$ from the University of Delhi. His interest lies in the field of accounting research with a special inclination to human resource.

Article submitted 2021-03-31. Resubmitted 2021-04-26. Final acceptance 2021-04-26. Final version published as submitted by the authors. 